\title{
A QUALITATIVE EXPLORATION OF STUDENT PERSPECTIVES ON SOCIAL MEDIA USE, ABUSE AND CONTENT
}

\author{
James "Mick" Andzulis, University of Alabama, USA \\ Jessica L. Ogilvie, University of Alabama, USA \\ Catherine M. Johnson, University of Alabama, USA \\ Lenita M. Davis, University of Alabama, USA
}

\begin{abstract}
We review relevant literature from the social media domain, identifying common research foci, as well as a gap and justification for this study which seeks to bring about a better understanding of, and contribute to, the nascent literature stream in the field of social media marketing research. We investigate just exactly how this powerful new force, social media, is being adopted, utilized and leveraged by students, the one group of individuals most likely to walk a delicate balance between personal and (budding) professional lives. We then share four major themes (ease of use, self-censoring and privacy, community and collectivism, and relationships with brands and businesses) and eighteen sub-themes which capture the essence of the impact this phenomenon is having on our target population. We conclude with a discussion of the findings and their associated implications, as well as insight into the limitations of our study and ideas for future research.
\end{abstract}

References available upon request 